\title{
Physicochemical and technological features of creating metal-based high-superalloys*
}

\author{
Eugene N. Kablov ${ }^{\ddagger}$ and Nikolay V. Petrushin \\ All-Russia Institute of Aviation Materials, 17 Radio St., Moscow 107005, Russia
}

\begin{abstract}
The analysis of modern nickel-based superalloys evolution for casting single-crystal turbine blades was performed. The influence of rhenium as a new alloying element on the physicochemical, kinetic, and structural parameters of nickel-based superalloys and phase stability is discussed. The following experimental data are generalized: the coefficients of segregation and distribution of alloying elements in nickel-based superalloys $\gamma$ - and $\gamma^{\prime}$-phases, the influence of alloying elements on the melting temperature, $\gamma$ - and $\gamma$-phases crystal lattice parameters, diffusion rate of atoms and probability of topologically closepacked (TCP) phase formation. The principles of the balanced alloying and computerized design method for developing fourth-generation single-crystal nickel-based superalloys with high Re content (9-10\%) are considered. The role of high gradient directional solidification $\left(200-220{ }^{\circ} \mathrm{C} \cdot \mathrm{cm}^{-1}\right)$ in producing single-crystal turbine blades of nickel-based superalloys with high Re content is discussed.
\end{abstract}

\section{INTRODUCTION}

Among the high-temperature structural materials, nickel-based superalloys gain first place by the volume of production and application. Nickel-based superalloys are used for manufacturing blades, vanes, and the majority of the other parts of the hot gas path for civil and military aircraft gas turbine engines, and also for stationary gas turbine plants.

All of these superalloys have multicomponent alloying and heterogene structure in which $\gamma^{\prime}$-phase highly dispersed particles based on $\mathrm{Ni}_{3} \mathrm{Al}$ and nickel $\gamma$-solid solution are the main constituents. In boron- and carbon-bearing nickel-based superalloys, carbide and boride phases of different type are also formed. Besides depending on alloying and the conditions of solidification and heat treatment, the phases may be formed in superalloys with the structure differed from the FCC structure of nickel (structure $\mathrm{A} 1)$ and $\gamma$-phase (structure $\mathrm{L1}_{2}$ ).

Since the 1960s, the main tendency in developing nickel-based superalloys for casting turbine blades was the constant increase of strengthening $\gamma$-phase quantity (up to 60-70\%) in the matrix $\gamma$-solution and complete $\gamma^{\prime}$-phase (solvus $\gamma^{\prime}$ ) dissolution temperature. It is achieved owing to the increase of $\mathrm{Al}$ concentrations in superalloys, the decrease of $\mathrm{Cr}$ content and additional alloying by the refractory transition metals (Mo, W, Nb, Ta, Hf) and also by the introduction of microadding (B, Zr, Y, La, Ce). In the technology of manufacturing turbine blades, the transition from ordinary casting to the directional solidification and to single-crystal casting is observed. The use of blades with columnar grains and single-crystal blades produced from the industrial superalloys allowed us to increase turbine entry gas temperature by $100-150{ }^{\circ} \mathrm{C}$. However, the long-term service of such blades showed that for the realization of the potential possibilities of single-crystal structure, it is necessary to develop special nickel-based

*Plenary lecture presented at the XVII Mendeleev Congress on General and Applied Chemistry, Kazan, Tatarstan, Russia, 21-26 September 2003. Other presentations are published in this issue, pp. 1605-1798.

¥Corresponding author: E-mail: admin@ viam.ru 
superalloys. As a result, first-generation single-crystal superalloys have been developed that provided the increase of blade operating temperature by $\sim 20^{\circ} \mathrm{C}$. The idea of alloying such superalloys is easy. Since there are no large-angle boundaries of grains in single crystal, the necessity of introducing elements and strengthening grain boundaries $(\mathrm{C}, \mathrm{B}, \mathrm{Zr}$, Hf) falls away. Though the content of these elements in traditionally alloyed superalloys is too small, nevertheless, their exclusion from the alloying complex led to significant changes of phase composition, phase transformation temperature, and mechanical properties. In particular, the absence of carbon and boron greatly increased the solidus temperature and mechanical and thermal fatigue resistance since it eliminated the formation of carbides as a stress concentrator and a source of cracking.

Further development of the single-crystal nickel-based superalloys was implemented owing to the improvement of metallurgical methods, to the use of charging material of high quality, and to new chemical elements for alloying. Thus, single-crystal alloys were developed in which one of the main alloying elements was rhenium. Rhenium concentration in second-generation nickel-based superalloys reaches $3-4 \%$ by mass, and in the alloys of the third-generation rhenium concentration increases up to $5-6 \%$ by mass $[1,2]$. Presently, nickel-based superalloys containing 9-12\% Re are being developed [3].

Rhenium-bearing superalloys [GS36 (2\% Re), GS32 (4\%Re), GS32M (5.5\% Re), GS47 $(9 \% \mathrm{Re})]$ have improved high-temperature long-term rupture strength, fatigue, and thermal stability; unlike traditionally alloyed superalloys, they have higher temperature capability by $\sim 50{ }^{\circ} \mathrm{C}$ (Fig. 1).

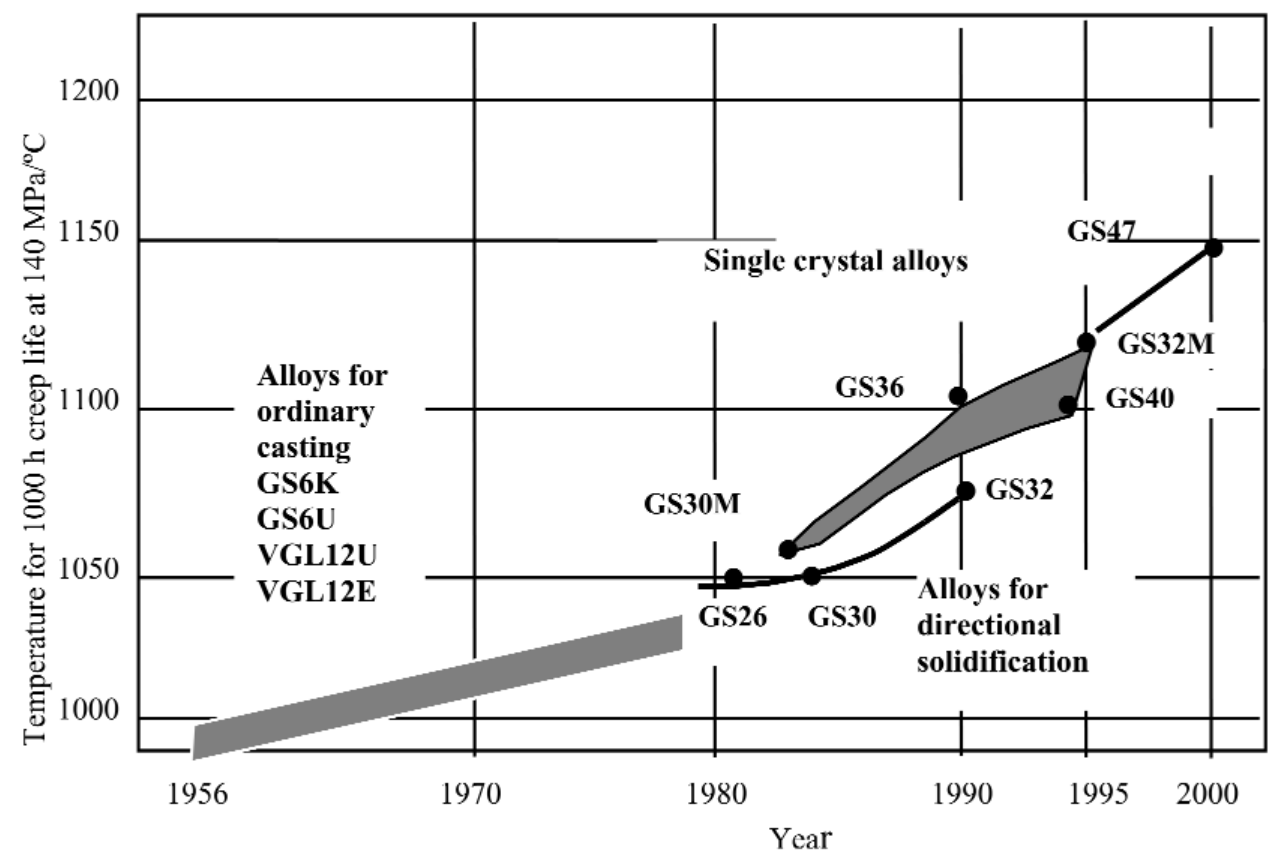

Fig. 1 The capability of nickel-based superalloys created by the All-Russia Institute of Aviation Materials.

For understanding the positive role of rhenium, it is necessary to find out its action on physicochemical, kinetic, and structural parameters of the nickel-based superalloys. Experimental results of the authors and the data published by the other investigators of this problem were generalized in this article [2-9]. 


\section{RESULTS AND DISCUSSION}

\section{Portioning behavior of alloying elements}

On producing single crystal of nickel-based superalloys by the directional solidification, chemical inhomogeneity occurring in casting is conditioned by microsegregation of the alloying elements within dendrite cells. The mechanisms of this process are determined by solidus and liquidus surface types on the state diagrams. The alloying element increasing the solidus and liquidus temperatures enriches dendrite axes, otherwise, it is concentrated in interdendritic regions.

In alloying complex, six refractory metals (namely, W, Re, Ru, Ir, Pt, and Co) increase the solidus and liquidus temperatures of binary nickel alloys, the rest of the alloying elements decrease them. As regards the solidus temperature of nickel-based superalloys, presently it was experimentally determined that alloying by W and Re significantly increases the solidus of these alloys [4,5] (Fig. 2), but Co and Pt do not have a considerable effect on the solidus. All the rest of the elements in the alloying complex decrease the solidus of these alloys in different ways.

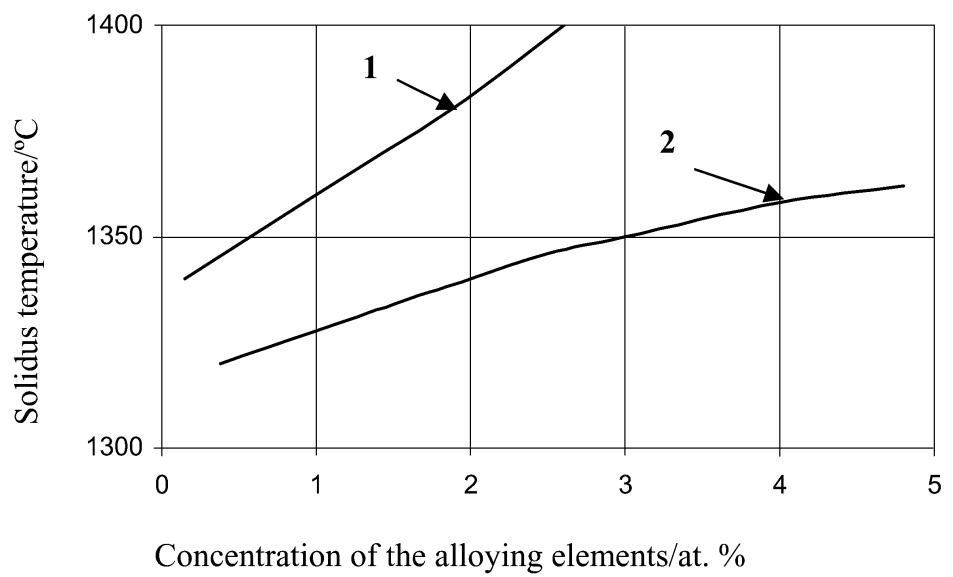

Fig. 2 Influence of the alloying elements of $\mathrm{Re}(1)$ and $\mathrm{W}$ (2) on the solidus temperature of nickel-based superalloys.

Quantitatively, on alloy solidification segregation of the alloying elements is characterized by segregation coefficients, $K_{\mathrm{s}}=C_{\mathrm{id}} / C_{\mathrm{ad}}$, where $C_{\mathrm{id}}, C_{\mathrm{ad}}$ - concentration of the alloying element in interdendritic regions and axes of dendrite, respectively.

Figure 3 shows typical values of direct and inverse segregation coefficients of alloying elements for the directional solidification of nickel-based superalloy single crystal.

Evidently, $\mathrm{Re}, \mathrm{W}, \mathrm{Ta}$, and $\mathrm{Nb}$ are the most highly segregating elements. Rhenium and tungsten segregate in the axes of dendrites, and tantalum and niobium enrich interdendritic regions according to the above-stated. The high segregation capability of rhenium and tungsten is not completely eliminated even during long-term high-temperature homogenization, which is one of the reasons harmful topologically close-packed (TCP) phases in nickel-based superalloy single crystals are formed.

Under the consideration of the state diagram of binary systems $\mathrm{Ni}-\mathrm{Cr}, \mathrm{Ni}-\mathrm{Mo}, \mathrm{Ni}-\mathrm{Pt}$, and general concepts on the dendrite segregation in nickel-based alloys, $\mathrm{Cr}$ and Mo must enrich interdendritic regions and $\mathrm{Pt}-$ dendrite axes. However, in reality, $\mathrm{Mo}$ and $\mathrm{Cr}$ segregate in dendrite axes and $\mathrm{Pt}$ in interdendritic regions. Presently, the reason for such abnormal behavior of these elements is not known.

The fundamental parameters of phase composition of single-crystal nickel-based superalloys are the volume fraction of $\gamma^{\prime}$-phase and distribution coefficients of alloying elements between the $\gamma^{\prime}$-phase 


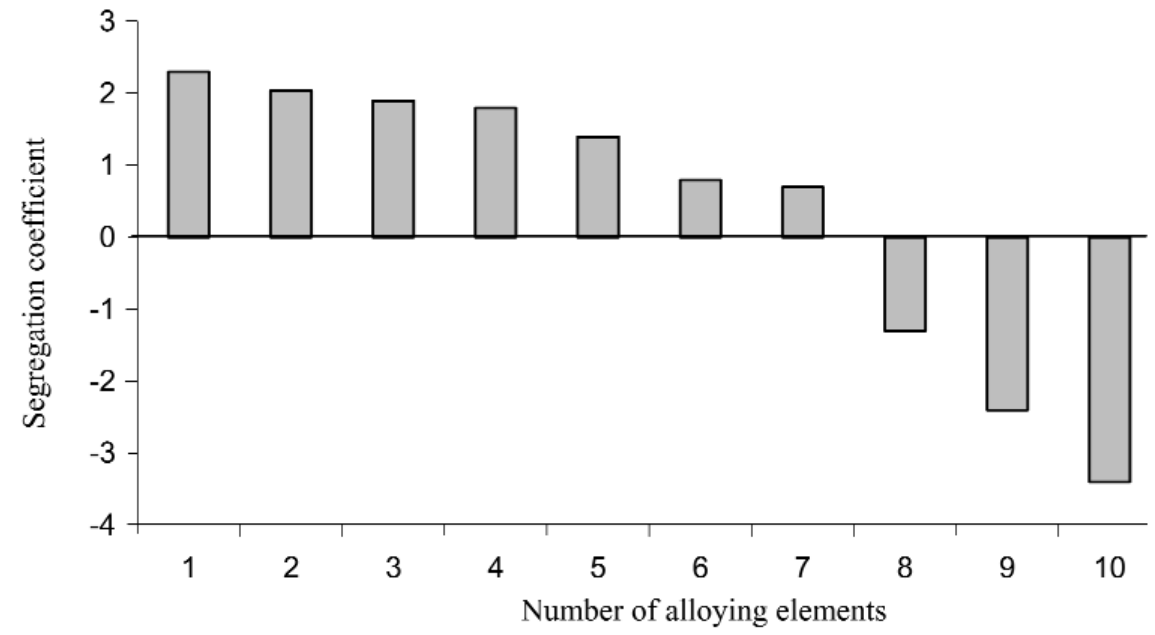

Fig. 3 Direct and inverse segregation coefficients of alloying elements Ta (1), Nb (2), Ti (3), Pt (4), Al (5), Mo (6), Cr (7), Co (8), W (9), Re (10).
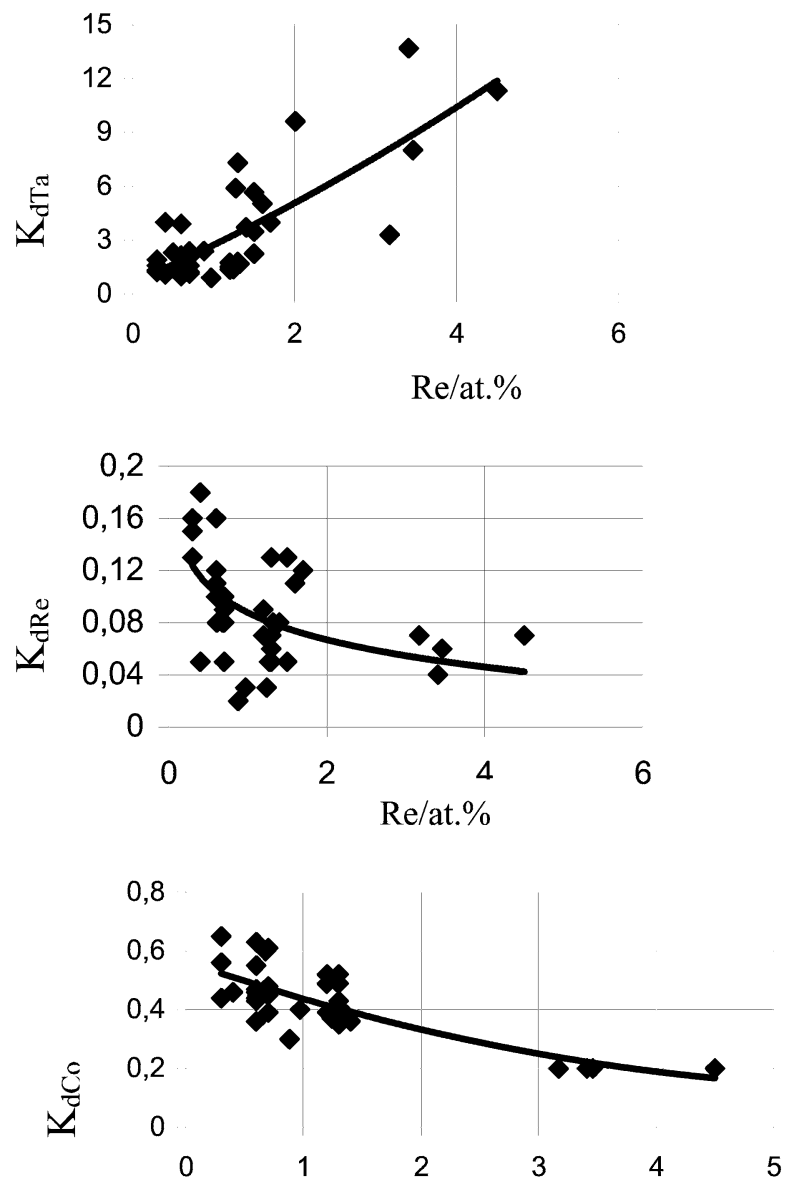

Re/at.\%

Fig. 4 The influence of rhenium on the distribution coefficients of alloying elements between $\gamma$ - and $\gamma$-phases in nickel-based superalloys. 
and the $\gamma$-solid solution $K_{\mathrm{di}}=C_{\gamma} / C_{\gamma}$, where $C_{\gamma}, C_{\gamma}$ is the concentration of the alloying element " $i$ " in the $\gamma^{\prime}$-and the $\gamma$-phases, respectively.

The alloying elements $\mathrm{Al}, \mathrm{Ti}, \mathrm{Ta}, \mathrm{Nb}, \mathrm{Pt}$ forming intermetallic compound of $\mathrm{Ni}_{3} \mathrm{X}$ type in nickelbased binary systems are $\gamma^{\prime}$-forming elements. They preferably dissolve in the $\gamma^{\prime}$-phase of nickel-based superalloy at $K_{\mathrm{dAl} \ldots \mathrm{Pt}}>1$. Elements $\mathrm{V}, \mathrm{Co}, \mathrm{Cr}, \mathrm{Mo}, \mathrm{Re}, \mathrm{Ru}$ form wide solid solution region in nickelbased binary alloys and that's why they mainly dissolve in the $\gamma$-phase, at $K_{\mathrm{dV}} \ldots \mathrm{Ru}<1$. Among all elements of the alloying complex, rhenium has the lowest solubility in the $\gamma^{\prime}$-phase. Figure 4 represents the experimental data on the coefficients of distribution of alloying elements between the $\gamma$-and $\gamma$-phases in the great group of nickel-based superalloys.

The data analysis shows that under the influence of rhenium, the distribution coefficients $K_{\mathrm{di}}$ greatly change: they increase for Ta and Ti and decrease for Co and Re. It is noted that $K_{\mathrm{dRe}}$ dependence of rhenium becomes asymptotic to the constant value equal to 0.05 . The change of $K_{d i}$-value for other alloying elements ( $\mathrm{Al}, \mathrm{Cr}, \mathrm{Mo}, \mathrm{Nb}, \mathrm{V})$ and quantity of the $\gamma^{\prime}$-phase in dependence of Re-content in alloy up to 4.5 at $\%$ is estimated as statistically insignificant.

\section{Kinetic parameters}

The rate of thermally activated processes leading to the structure change and alloy properties is determined by the kinetic parameters, in particular by diffusion coefficients of alloy component atoms. Under the high-temperature dissolution and coagulation of the particle of strengthening $\gamma$-phase, precipitation of TCP phases and others occur in nickel-based superalloy structure. The kinetics of these processes is verified by diffusion mass transport in solid solution.

It is known that between the diffusion coefficient, $D$, and the solidus temperature, $T_{\mathrm{S}}$, close correlation takes place [10]. Because $D=D_{0} \cdot \exp (-E / k \cdot T), E \approx 18 k \cdot T_{\mathrm{S}}$, then $D=D_{0} \cdot \exp \left(-18 / T_{\text {hom }}\right)$, where $T_{\text {hom }}=T / T_{\mathrm{S}}-$ homological temperature. It follows from this relationship if an alloying element increases the alloy solidus, as in the case of alloying nickel-based superalloys by tungsten and rhenium, then under the other equal conditions homological temperature and, consequently, diffusive mobility of atoms in such alloy will be lower.

Figure 5 shows experimentally determined correlation between the coefficient of nickel atoms self-diffusion in nickel-based superalloy single crystal at $900{ }^{\circ} \mathrm{C}$ and their solidus temperature. Evidently, with the increase of the solidus temperature, the self-diffusion coefficient decreases.

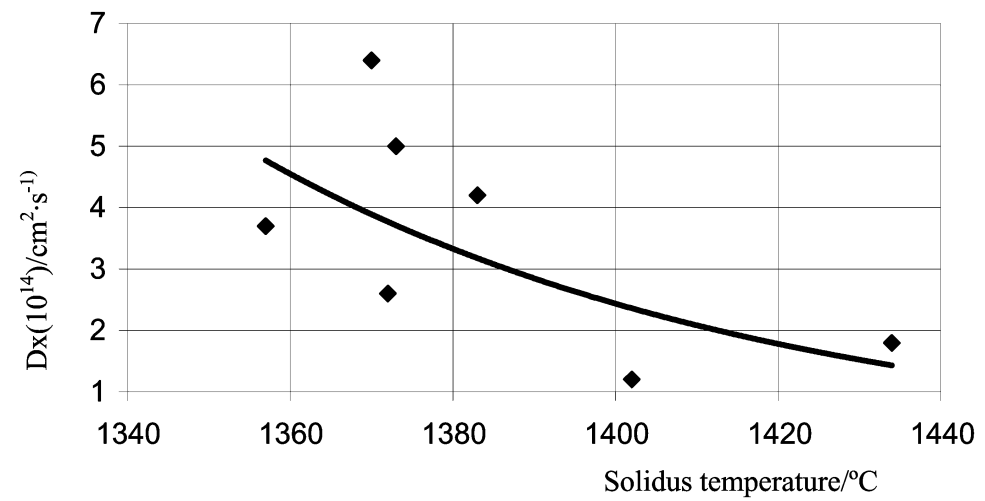

Fig. 5 The correlation between the coefficient of nickel atoms self-diffusion at $900{ }^{\circ} \mathrm{C}$ and solidus temperature of nickel-based superalloy single crystal.

The low rates of diffusion processes are one of the main reasons for high thermal stability of rhenium-bearing nickel-based superalloys. It is structurally revealed in forming more dispersed particles of 
a strengthening $\gamma^{\prime}$-phase at the decomposition of oversaturated $\gamma$-solid solution in the process of quenching from the temperature that is lower than the $\gamma$-solvus temperature and in their subsequent delayed coagulation rate under the long-term high-temperature tests.

\section{Structural-phase parameters}

Structural-phase parameters of nickel-based superalloys are the parameters of $\gamma$-solid-solution crystal lattice, $\gamma$-phase, and their dimension misfit. The lattice parameters of $\gamma$-solid solution and $\gamma^{\prime}$-phase are in close correlation with the concentration strengthening of solid solution of these phases and misfit parameter, with creep rate and other high-temperature mechanical properties of nickel-based superalloy single crystal. The nickel-based superalloys with maximum-phase lattice parameters are the most hightemperature creep rapture life alloys, and in this case, the solid-solution lattice parameter must be higher than the $\gamma^{\prime}$-phase lattice parameter.

Thus, a fundamental fact was established, that such structurally dependent macroscopic characteristic of nickel-based single crystal as stress rupture, 100 or $1000 \mathrm{~h}$ at $1000{ }^{\circ} \mathrm{C}$, greatly depends on a microscopic parameter, namely, the misfit of solid-solution crystal lattice parameter and strengthening phase $\gamma$. It should be noted that absolute value of this parameter ranges from 0.1 to $0.2 \%$; it corresponds to the parameter change of crystal lattices of both phases in the third-fourth sign after the comma.

It is experimentally established that the influence of alloying elements on the $\gamma$-phase crystal lattice parameter is not so significant as on that of the $\gamma$-solid solution of multicomponent nickel-based alloys (Fig. 6).

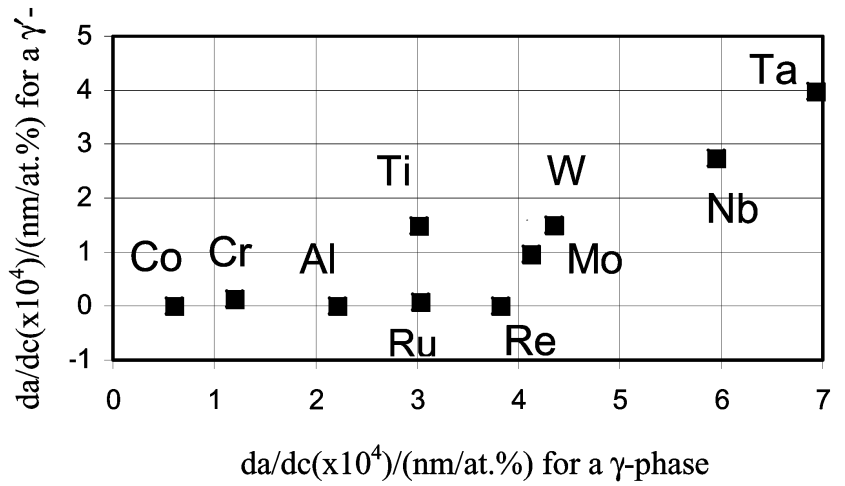

Fig. 6 Alloying influence on the $\gamma$-and $\gamma$-phase crystal lattice parameters in nickel-based superalloys.

Thus, the structural-phase parameters of the concentration strengthening are mainly determined by those alloying elements, which, to an even greater degree, change the lattice parameter of $\gamma$-solid solution. In the first place, it applies to such elements as W, Re, Mo, and Ta. It should be noted that the Ta effect prevails. However, it is necessary to note here that the strengthening effectiveness is determined not only by $d a / d c$ value ( $d a$ is a change of the crystal lattice parameter of the base on changing the alloying element concentration by $d c$-value), but also depends on the solubility, valency differences, and modulus of elasticity of the alloying metal and alloy base.

Therefore, in spite of the fact that rhenium occupies the second place in the above-mentioned row, its total contribution to the nickel-based solid solution strengthening is the greatest, as it has the larger modulus of elasticity and its concentration in nickel-based superalloys $\gamma$-phase is maximum. 


\section{Phase stability}

The phase stability of nickel-based superalloys is one of the important factors of high-temperature mechanical properties of turbine blades. The phase stability is the most important problem for rheniumbearing superalloys, as under unfavorable combination of alloying elements or because of their segregation, the TCP phases of different types may be formed in these alloys. The negative influence of these phases on the superalloy properties lies in the fact that these phases are the source of a premature nucleation and propagation of cracks, which cause the ductility decrease and brittle fracture. The other indirect reason of alloys loss of strength is conditioned by the fact that TCP phases bond a considerable amount of refractory metals, as a result of which $\gamma$ - and $\gamma^{\prime}$-phases are depleted in these metals that decrease the effectiveness of the concentration solid-solution and precipitation strengthening. In this case, the important structural-phase stability parameters such as diffusion rate of atoms, misfit between the crystal lattice parameters of $\gamma$ - and $\gamma^{\prime}$-phases, and others change adversely.

For estimation of the superalloy phase stability, different methods of computation are used. Among them, the most known methods are PHACOMP $\left(\bar{N}_{v}\right)$ [11], NEW-PHACOMP $(M \bar{d})$ [12], and SOLUBILITY INDEX $(S I)$ [13].

The advanced development in this field is the formulated by Morozova G.I., All-Russian Institute of Aviation Materials (VIAM), empirical equation of alloying balance, linking the atomic mass of the alloy $\left(\bar{A}_{a}\right)$ with the average concentration of valence electrons $\left(\bar{E}_{a}\right)$ of the alloy constituent elements [14]:

$$
\left\{\begin{array}{l}
\Delta E=\bar{E}_{a}-E_{0}=0 \\
E_{0}=0.036 \bar{A}_{a}+6.28
\end{array}\right\}
$$

Here, $\bar{A}_{a}=\sum_{i=1}^{n} A_{i} \cdot C_{i} ; \bar{E}_{a}=\sum_{i=1}^{n} E_{i} \cdot C_{i} ; \quad$ where $A_{i}, C_{i}, E_{i}$ are the atomic mass, concentration, and quantity of valence electrons (sp: the aluminum electrons; ds: transition-metal electrons), respectively, of the " $i$ " constituent element, $n$ is quantity of the alloy constituent elements. The deviation of $\Delta E$ from zero value is indicative of high probability of the phase transformation course: formation of $\mathrm{Me}_{6} \mathrm{C}$ carbides or TCP phases at $\Delta E<0$ and $\gamma-\gamma^{\prime}$ eutectic phases or phases of $\mathrm{Ni}_{3} \mathrm{Ti}\left(\mathrm{Ni}_{3} \mathrm{Nb}\right)$ type at $\Delta E>0$.

The estimation method of nickel-based superalloys phase stability according to eq. 1, $\Delta E$-method, advantageously differs from PHACOMP $\left(\bar{N}_{v}\right)$, NEW-PHACOMP $(M \bar{d})$, and SOLUBILITY INDEX $(S I)$ methods by the absence of the necessity of experimental determination of the parameter critical values, $\bar{N}_{v}$ and $M \bar{d}$, for different alloying systems.

The analysis of calculated values of $\Delta E$ parameter for known single-crystal nickel-based superalloys (Fig. 7) testifies to the chemical composition unbalance of most of these alloys.

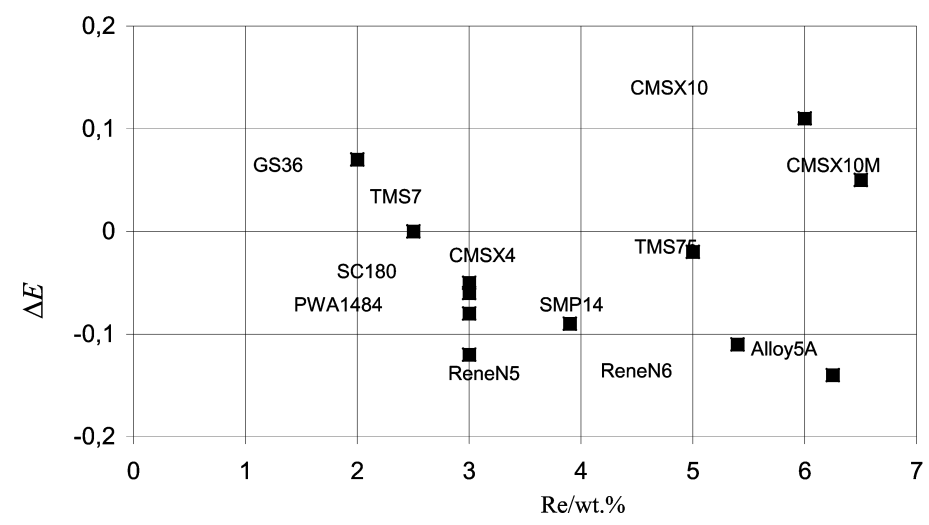

Fig. 7 Values $\Delta E$ parameter predicting the TCP and other unfavorable phases formation in the structure of singlecrystal nickel-based superalloys. 


\section{Method of computerized design}

For a long time, the empirical "trial-and-error" method was the main method used for metal-based highsuperalloy development. It is quite apparent that the development of the optimal composition and properties complex for nickel-based superalloys alloyed by more than 15 elements is a highly laborious task requiring much time and financial expenditure. It especially concerns the alloys alloyed with expensive elements such as rhenium, ruthenium, and others. In general, it is possible to calculate the chemical composition of alloys on the basis of first principles using the thermodynamic and kinetic equations. However, at present, the decision of such a task is hardly probable.

In this connection, the formal methods of computerized design of modern superalloys are the necessary means [15]. Essentially, the traditional "trial-and-error" method is replaced by the proximate and economical method "do rightly from the very first", which allows us to optimize not only the chemical compositions of already available commercial alloys, but also to develop new ones.

General conclusion and analysis of numerous experimental data permit us to determine the influence of alloying elements on the phase composition, physicochemical, structural-phase, thermophysical, and high-temperature properties of nickel-based alloys. As a result of the statistical treatment of numerous experimental data files, the regression equations were derived which permit us to calculate the above-mentioned characteristics for any new nickel-based superalloys being developed. This approach was realized by authors during the development of the computerized design method of cast nickel-based superalloys, which includes the calculation of phase composition, phase stability parameters, physicochemical, structural-phase, thermophysical, and high-temperature characteristics of nickel-based superalloys (Fig. 8).

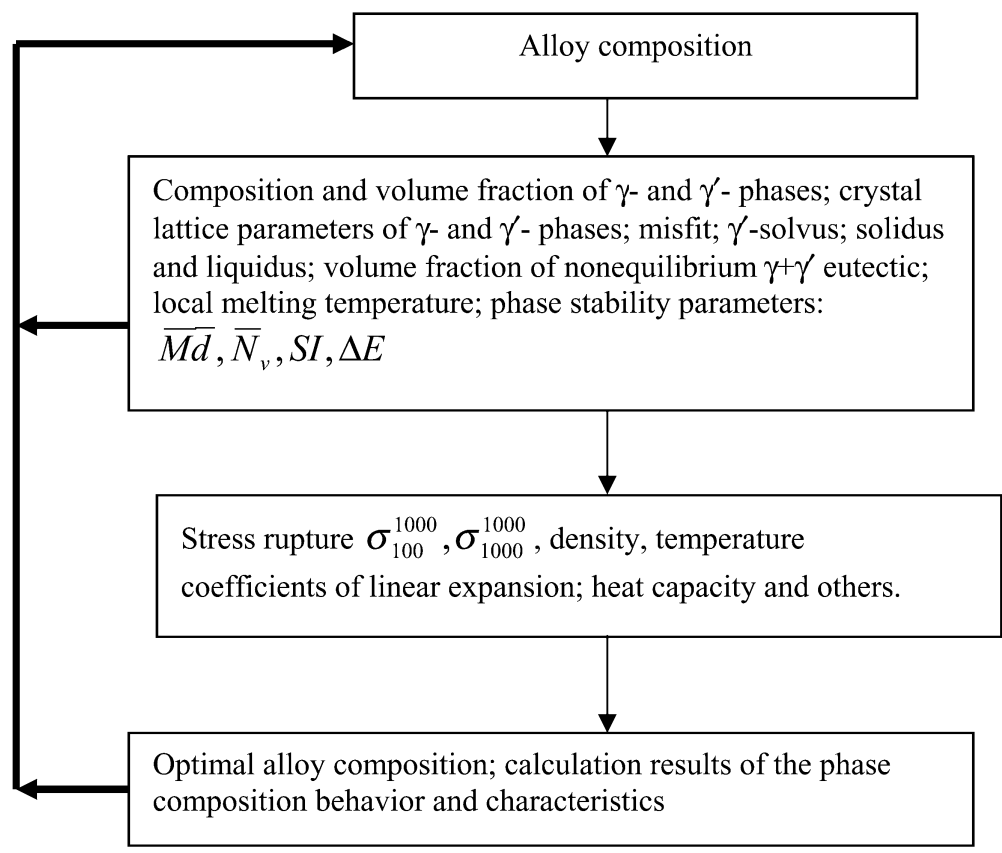

Fig. 8 Calculation scheme of the optimal composition and properties in the course of computerized design of nickel-based superalloys. 
Selection of the optimal composition is performed on the basis of accomplishing the balanced alloying principles that include the given values of parameters for being developed alloy which determine its high-temperature creep strength and capability. Such parameters are the following:

- $\quad$ volume fraction of cubiform $\gamma^{\prime}$-phase high dispersion particles $(0.3-0.5 \mu)$, for strengthening the matrix $\gamma$-solid solution, it must be 60-70\%;

- $\quad$ volume fraction of eutectic origin nonequilibrium phases, for decreasing microporosity, it must be minimum;

- full dissolution temperature of $\gamma^{\prime}$-phase in $\gamma$-solid solution ( $\gamma^{\prime}$-solvus), which characterizes not only the thermal stability of the heterophase $\gamma / \gamma^{\prime}$-structure, but also determines, on a first approximation, the high-temperature properties of alloys: the high-temperature stress rupture of nickelbased superalloys improves with increasing $\gamma^{\prime}$-solvus;

- $\quad$ solidus temperature: if alloying increases the solidus, the diffusion mobility of atoms in such an alloy will be little;

- $\quad$ crystal lattice parameters of $\gamma$-solid solution and $\gamma^{\prime}$-phase and dimension misfit: for achieving the high creep resistance, the lattice parameters of $\gamma$ - and $\gamma^{\prime}$-phases must be maximum, and in this case the lattice parameters of $\gamma$-solid solution must be larger than that of $\gamma^{\prime}$-phases;

- melting temperature of nonequilibrium phases of eutectic origin: to increase the heat treatment "window", the melting temperature must be maximum, otherwise, it is impossible to dissolve $\gamma$-phases completely and perform the total homogenization of $\gamma$-solid solution without risk of the interdendritic regions flashing;

- $\quad$ solidification temperature range: to increase the alloy tendency to the formation of columnar and single-crystal structures and to minimize the volume fraction of microporosity during the directional solidification, it must be minimum;

- density, temperature coefficients of linear expansion; heat capacity;

- $\quad$ average number of electron vacancies for the $\gamma$-matrix alloying elements, $\bar{N}_{v}$; average energy level of d-orbital atoms for $\gamma$-matrix alloying elements, $M \bar{d}$; solubility index of alloying elements in $\gamma^{\prime}$-phase, $S I$; difference of the valence electron average concentrations for alloying elements of the alloy, $\Delta E$, and others; critical values of these parameters determine the probabilities of phase transformation progress of different types.

Using the computerized design method, the fourth-generation single-crystal nickel-based superalloy has been developed, namely, GS47 alloy (density $9.1 \mathrm{~g} \cdot \mathrm{cm}^{-3}$ ) with rhenium content of $9 \mathrm{wt} \%$ [3]. In its high-temperature strength in the range of $900-1100{ }^{\circ} \mathrm{C}$ and durability up to $1000 \mathrm{~h}$ and more $\left(\sigma_{1000}^{900} \geq 430 \mathrm{MPa}, \sigma_{1000}^{1000} \geq 220 \mathrm{MPa}, \sigma_{1000}^{1100} \geq 100 \mathrm{MPa}\right)$ the GS47 superalloy is superior to the known third-generation single-crystal nickel-based superalloys [16].

\section{High-gradient technology}

Successful development of high-superalloys should be impossible without creation of a special technology of single-crystal casting. At present, VIAM is the only enterprise in the world that has developed and uses the high-gradient technology and special equipment for manufacturing the single-crystal turbine blades by directional solidification method [2].

In the manufacture of single-crystal blades from superalloys according to the available in the industry directional solidification methods with low-temperature gradient $\left(10-30{ }^{\circ} \mathrm{C} \cdot \mathrm{cm}^{-1}\right)$, the size of the solid-liquid zone in the casting being solidified achieves tens of millimeters. Consequently, because of overlapping interdendritic channels by the second-order dendritic cores, the melt flow in them becomes difficult. As a result, during the solidification of interdendritic liquid, the interdendritic pores are formed in consequence of the molar volume differences of liquid and solid phases. In addition, the casting produced by low-gradient technology is characterized by a coarse dendritic structure (distance between dendrite axes achieves $400-800 \mu$ ) with developed second-order axes. At this point, the higher 
segregation of alloying elements takes place, which results in the formation of large precipitates of the eutectic origin phases in the interdendritic regions. It should be noted that in the manufacturing blades of rhenium-bearing superalloys, by this technology it is impossible to eliminate completely the formation of growth defects such as "freckles", which disrupt the single-crystal structure of blades.

In the case of the high-gradient method of directional solidification with temperature gradient of $200-220^{\circ} \mathrm{C} \cdot \mathrm{cm}^{-1}$, the size of the solid-liquid zone decreases. As a result, the dendritic segregation substantially decreases that leads to the reduction of micropore size and volume fraction. In this case, in the single-crystal casting, the following phenomena are observed: the formation of a more homogeneous structure of the superalloy with significantly small distances (2-3 times) between dendrite axes, the formation of eutectic origin nonequilibrium phases is suppressed, and the formation of "freckle"type defects is totally eliminated. The process of high-gradient directional solidification permits us to produce the blades of nickel-based superalloys with a high content of rhenium having essentially more perfect single-crystal structure and makes their heat treatment more economic.

It is well known that the homogenization time on heat treatment of superalloys is determined by the distance between the dendrite axes of the first order. Hence, it follows that the lesser homogenization time is required for single crystals with smaller interdendritic distances, i.e., solidified with hightemperature gradient. This fact is excessively important for the homogenization of blades of rheniumrich superalloys in which the diffusion flows in $\gamma$-solid solution of dendrites and interdendritic regions are controlled by diffusion of rhenium and tungsten atoms as their diffusion coefficients are low. For example, the homogenization time of the well-known third-generation single-crystal nickel-based superalloy, CMSX-10 (6\% Re), is $30-35 \mathrm{~h}$ at $1366^{\circ} \mathrm{C}$ [1]. Whereas for GS47 (9\% Re) superalloy single crystals produced by the high-gradient technology, we succeeded in decreasing the homogenization time up to $20 \mathrm{~h}$ at $1335^{\circ} \mathrm{C}$.

\section{Tendencies of creating nickel-based superalloys}

The analysis of developments in the field of high-temperature materials allows us to determine the main tendencies in the modern growth of nickel-based superalloys for gas turbine single-crystal blades. These tendencies are as follows:

- $\quad$ use of elements such as rhenium, ruthenium, platinum, iridium, and osmium in the development of new alloys to increase their operating temperature level;

- $\quad$ use of yttrium and rare-earth metals such as lanthanum and cerium as microalloying additions for strengthening substructure defects of single crystal and improving gas corrosion resistance;

- decrease of nitrogen and oxygen content up to less than 10 ppm each;

- $\quad$ decrease of sulfur content up to 5 ppm;

- production of single-crystal blades by high-gradient directional solidification method with the temperature gradient on the growth front of $200-220^{\circ} \mathrm{C} \cdot \mathrm{cm}^{-1}$ instead of $10-30{ }^{\circ} \mathrm{C} \cdot \mathrm{cm}^{-1}$, realizing the advantages of rhenium-bearing nickel-based superalloys;

- development of special heat treatment conditions, realizing the advantages of single-crystal alloys;

- creation of special protective coatings and methods of their applying on the part surfaces made of single-crystal alloys;

- $\quad$ use of the computerized design methods, which permit us to quickly and reliably find the optimal alloy compositions providing the predetermined level of service properties in the development of new superalloys. 


\section{REFERENCES}

1. G. L. Erickson. J. Metals 47 (4), 36-39 (1995).

2. E. N. Kablov. Gas Turbine Cast Blades (Alloys, Technology, Coatings), p. 632, Institute of Steels and Alloys, Moscow (2001).

3. E. N. Kablov, A. V. Logunov, I. M. Demonis, N. V. Petrushin, V. V. Sidorov. RF Patent 2153021 , Int. Cl. C22 C 19/05, Filed 06 January 1999, Issued 20 July 2000.

4. E. N. Kablov, I. L. Svetlov, N. V. Petrushin. Materialovedenie (4), 32-38 (1997).

5. E. N. Kablov, I. L. Svetlov, N. V. Petrushin. Materialovedenie (5), 14-17 (1997).

6. R. E. Shalin, I. L. Svetlov, E. B. Kachanov, V. N. Toloraiya, O. S. Gavrilin. Single Crystal of Nickel-Based Superalloys, p. 36, Mashinostroenie, Moscow (1997).

7. E. N. Kablov, N. V. Petrushin, L. B. Vasilenok, G. I. Morozova. Materialovedenie (2), 23-29 (2000).

8. E. N. Kablov, N. V. Petrushin, L. B. Vasilenok, G. I. Morozova. Materialovedenie (3), 38-43 (2000).

9. N. V. Petrushin and I. L. Svetlov. Metals (2), 63-73 (2001).

10. B. S. Bokshtein, S. Z. Bokshtein, A. A. Zhukhovitsky. Thermodynamics and Kinetics of Diffusion in Solids, p. 279, Metallurgiya, Moscow (1974).

11. S. T. Sims. In Superalloys II, S. T. Sims, N. S. Stoloff, W. C. Hagel (Eds.), pp. 217-240, WileyInterscience, New York (1987).

12. N. Yukawa, M. Morinaga, H. Ezaki, Y. Murata. In High Temperature Alloys for Gas Turbines and Other Applications, Proc. of conf. held in Liege, Belgium, 6-9 October 1986, W. Betz et al. (Eds.), pp. 935-944, C.R.M., Dordrecht (1986).

13. H. Harada, M. Yamazaki, Y. Koizumi, N. Sakuma, N. Furuya, H. Kamiyal. In High Temperature Alloys for Gas Turbines, Proc. intern. conf. held in Liege, Belgium, 4-6 Oct. 1982, pp. 721-735, Reidel Publishing (1982).

14. G. I. Morozova. Report of Academy of Science USSR. 320 (6), 1413-1416 (1991).

15. H. Harada, K. Ohno, T. Yamagata, T. Yokookawa, M. Yamazaki. In Superalloys 1988, S. Reichman et al. (Eds.), pp. 733-742, Metallurgical Society, Seven Springs, Mountain Resort, USA (1988).

16. G. L. Erickson. In Superalloy 1996, R. D. Kissinger, D. J. Deye, D. L. Anton, A. D. Cetel, M. V. Nathal, T. M. Pollock, D. A. Woodford (Eds.), pp. 35-43, The Minerals, Metals, Materials Society, Warrendale, PA, USA (1996). 